\title{
Transbronchial biopsy as a tool to evaluate small-airways disease in asthma. Pros
}

\author{
L-P. Boulet
}

Asthma is an inflammatory disease and although the existence of small airways disease has been described, a few decades ago, in asthma and chronic obstructive pulmonary disease (COPD), the possibility that small airway inflammation/remodelling is involved in the pathophysiology and clinical manifestations of these conditions has recently been re-emphasised [1-3]. Previous observations had shown small airways changes in asthma. Using surgically resected lung specimen of patients with asthma, HAMID et al. [1] observed an airway inflammatory process not only in large but also small airways, activated eosinophils being more numerous in peripheral airways. Smallairways disease has also been found in fatal asthma [4]. The inner-wall area of distal airways was found to be increased in patients who died of asthma or other causes; structural changes such as smooth-muscle thickening were observed in peripheral airways. There was an increased interest in exploring small-airways inflammation, with the development of new medications such as hydrofluoroalkanes-propelled beclomethasone (QVAR ${ }^{\mathrm{TM}}$, 3M Pharmaceuticals, St-Paul, MN, USA). This drug has an increased peripheral lung deposition that can help reduce peripheral-airway inflammation and induced-lung hyperinflation, but its effects on small airways remain to be explored further $[5,6]$.

Sophisticated imaging techniques have provided some information about small airways but cannot reveal the nature of the process involved [5]. Bronchoalveoloar lavage (BAL) can help to characterise inflammatory events occurring in the peripheral airways [7, 8]. However, these may be different from those of the airway wall and BAL does not provide information on changes in airway structure. Endobronchial biopsies of lobar, segmental and subsegmental bronchi have been used in the last two decades to study the physiopathology of asthma and other diseases; this procedure can be carried out safely and is increasingly standardised [8]. However, it has been more difficult to analyse changes at the level of small airways and apart from looking at surgical specimens from asthmatic patients, which are rare, the possibility of obtaining transbronchial biopsies (TBB) for this purpose could be useful [9-11]. The main goal of such a procedure in the context of studies on asthma

Correspondence: L-P. Boulet, Hôpital Laval, 2725, chemin SainteFoy, Sainte-Foy(Québec), Canada, GIV 4G5. Fax: 4186564762. E-mail: lpboulet@med.ulaval.ca pathophysiology is therefore to evaluate peripheral airways and lung parenchyma. The study by BALZAR et al. [11] shows that in addition to alveolar tissue, small airways can be sampled by TBB, allowing for the analysis of inflammation and tissue remodelling at this level in asthma. Small airways had higher cell counts than medium or large airways and the findings in TBB were similar to surgical samples available in three patients.

As indicated in the paper by BALzAR et al. [11], a limited number of small airways can be obtained for analysis. Out of 29 transbronchial biopsies, 45\% had small airways [11]. However, this seems sufficient to gather the information expected. There may be differences in the density of inflammatory cells in the different parts of the lung, making it difficult to infer what is happening at the whole-lung level with only this number of specimens. The report from BALZAR et al. [11] indicated that the ratio of individual inflammatory cell types was similar among lung regions, except for an increase in the percentage of monocytes/ macrophages in alveolar tissue. Nevertheless, more data should be obtained on the reproducibility of results before $\mathrm{TBB}$ is used in pharmacological or bronchoprovocation studies.

With regards to the ethical issues, such a procedure has the potential for significant side-effects and should be performed by experienced investigators with all the necessary precautions. Among the most feared effects are bleeding or pneumothorax induced by the procedure $[12,13]$. Precautions to avoid or treat these potential problems, such as the use of fluoroscopy to direct the forceps, possibility of rapid chest-tube insertion, postprocedure radiograph and avoidance of drugs acting on coagulation, are mandatory. These procedures have however, been performed for a few decades under various conditions, mostly interstitial lung diseases, and a significant experience has been acquired with TBB. In experienced hands this technique has a good safety record [12-14]. As described by BALZAR et al. [11], in their hands, this procedure was safe and not associated with significant adverse events, even in severe asthmatics; in a series of $\sim 100$ bronchoscopies with $\mathrm{TBB}$, there was a report of only one case of pneumothorax, which was treated conservatively.

To conclude, transbronchial biopsies may help to understand the contribution of peripheral airways to asthma pathophysiology. It also seems reasonable to consider using transbronchial biopsies for research, 
in experienced hands and for selected investigations where the benefits and the expected findings are considered to justify the procedure. Its potential clinical use in selected cases of asthma needs to be documented further.The safety record of transbronchial biopsies in asthma patients is good but should continue to be closely monitored. However, the type of data gathered is important to the understanding of the role of peripheral inflammation in patients with asthma, particularly when severe and refractory to steroid treatment.

\section{References}

1. Hamid Q, Song Y, Kotsimbos TC, et al. Inflammation of small airways in asthma. J Allergy Clin Immunol 1997; 100: 44-51.

2. Martin RJ. Therapeutic significance of distal airway inflammation. J Allergy Clin Immunol 2002; 109: 447 446.

3. Shaw RJ, Djukanovic R, Tashkin DP, Millar AB, duBois RM, Corris PA. The role of small airways in lung disease. Respir Med 2002; 96: 67-80.

4. Carroll N, Elliot J, Morton A, James A. The structure of large and small airways in nonfatal and fatal asthma. Am Rev Respir Dis 1993; 147: 405-410.

5. Goldin JG, Tashkin DP, Kleerup EC, et al. Comparative effects of hydrofluoroalkane and chlorofluorocarbon beclomethasone dipropionate inhalation on small airways: assessment with functional helical thin-section computed tomography. J Allergy Clin Immunol 1999; 104: S258-S267.

6. Leach C. Effect of formulation parameters on hydrofluoroalkane-beclomethasone dipropionate drug deposition in humans. J Allergy Clin Immunol 1999; 104: S250-S252.

7. European Society of Pneumology Task Group. Technical recommendations and guidelines for bronchoalveolar lavage (BAL). Eur Respir J 1989; 2: 561-585.

8. Workshop summary and guidelines. Investigative use of bronchoscopy, lavage and bronchial biopsies in asthma and other airway diseases. Allergy Clin Immunol 1991; 88: 808-814.

9. Kraft M, Martin RJ, Wilson S, Djukanovic R, Holgate ST. Lymphocyte and eosinophil influx into alveolar tissue in nocturnal asthma. Am J Respir Crit Care Med 199; 159: 228-234.

10. Kraft M, Djukanovic R, Wilson S, Holgate ST, Martin JR. Alveolar tissue inflammation in asthma. Am J Respir Crit Care Med 1996; 154: 15051510.

11. Balzar S, Wenzel SE, Chu HW. Transbronchial biopsy as a tool to evaluate small airways in asthma. Eur Respir J 2002; 20: 254-259.

12. Bollinger CT, Mathur PN. ERS/ATS Statement on interventional pulmonology. Eur Respir J 2002; 19: 365-373.

13. Hernandez Blasco L, Sanchez Hernandez IM, Villena Garrido V, de Miguel Poch E, Nunez Delgado M, Alfaro Abreu J. Safety of the transbronchial biopsy in outpatients. Chest 1991; 99: 562-565.

14. Ahmad M, Livingston DR, Golish JA, Mehta AC, Wiedemann HP. The safety of outpatient transbronchial biopsy. Chest 1986; 90: 403-405. 